tion of malocclusion, the orthodontist finds himself confronted with one of the most difficult problems with which he has to deal (Figs. 8, 9, and 10).

Normal variations of form in the muscles of the lips, cheek and tongue are also recognized, as well as deviations in the size of the oral aperture, termed microstomia and macrostomia. The relation of the hy line to the oeclusal plane of the teeth varies considerably, and it is also a matter of common knowledge that so prominent a feature of the face as the nose varies greatly in size and form, even within normal limits. Again, no two beings have eyes that are alike, for these, too, vary greatly in their color, size and position.

The principal features of the face which are the special concern of the orthodontist are shown in Figs. 11 and 12 . The relative place which each of these features ought to occupy constitutes the student's first object of study. Having secured in his mind the position and form of each part, he comes to the sccond problem, viz., The rearrangement of malplaced and malfomed parts in the faces of his patients. That this can frequently be done is one of the many notable achievements of the modern art of orthodontics.

to be continued ?

\title{
THE TEETH AS FACTORS IN THE ECONOMY OF THE ANIMAL KINGDOM
}

\author{
By Martin Dewey, D.D.S., M.D., Kansas City, Mo. \\ Professor of Dental Anatomy and Orthodontia, Kansas City Dental College; President \\ of the Dezey Sichool of Orthodontia.
}

$\mathrm{T}$ HE conviction has often been forced on those engaged in the practice of orthodontia that the majority of individuals seeking the service of an orthodontist for the treatment of malocclusion in children do so with the idea of improving the facial bcauty of the child. It is very seldom that the orthodontist is called on to correct a case of malocclusion for the purpose of increasing the masticating efficiency of the teeth. It is also true that the majority of people who seek the service of a dentist do so for the purpose of alleviating pain instead of increasing the masticating efficiency of the dental apparatus. In fact, those who are engaged in the construction of crowns and bridges are often compelled to have a long argument with the patient in regard to the necessity of having a bridge inserted before the patient will consent to have such work done. In other words, the majority of people who engage the service of the dentist or orthodontist do so with the idea of being relieved of pain by the one or having something done by the other which will increase their facial beauty. This idea is entirely wrong, for the aim of all dental operations, whether of an orthodontic or other character should be to increase the masticating efficiency of the dental apparatus. While it is apparent to every one practicing orthodontia or dentistry that teeth in malocclusion do not perform their function as well as when in normal occlusion, nevertheless it is probable that few people have considered the important factor the teeth have played in 
the preservation of animal life. Very few people realize that the animal kingdom, as we find it today, would not exist if it were not for the teeth. We often speak of the intricate workings of the brain, the wonderful effects of the human mind, and are even impressed with the intelligence displayed by certain lower animals, yet comparatively few people realize that the brain would never have developed, the human mind would never have been so powerful, even the lower animals would not exist as they are found today, if it had not becn for the dental apparatus. There probably has been no one other set of organs which

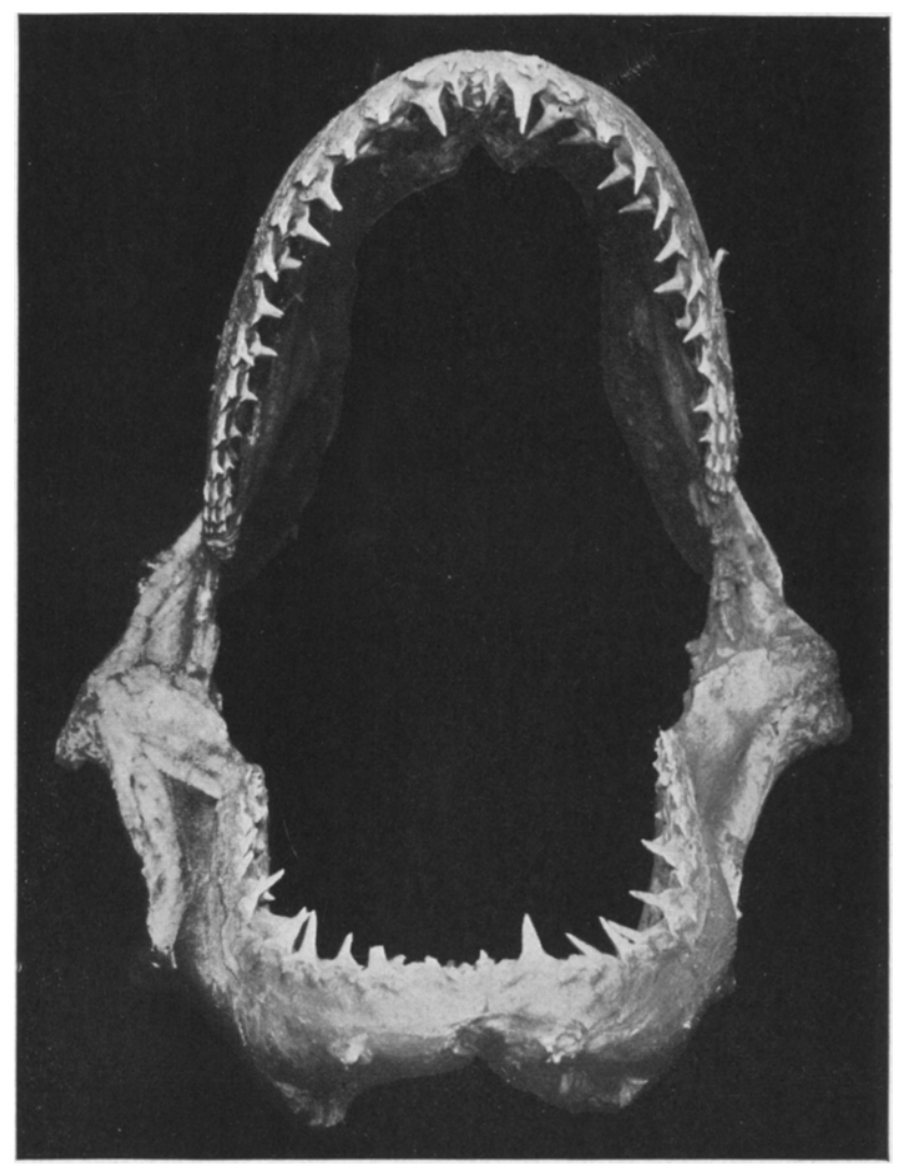

Fig. 1.-Jaws of Shark (species unknow11).

has been to such an extent responsible for the development of the animal kingdom, or which has played such an important part in the different kinds of animal life, as have the teeth. It is a fact that comparatively few persons sufficiently appreciate their dental apparatus, and probably the majority of the lower animals are not troubled about "oral hygiene" for, fortunately, most of them are not subject to dental ills if they are living in the natural environment in which their teeth developed. It may be taken for granted that, without the development of the dental apparatus in the various animals as we find it today, such animals would not be in existence. In fact, without the development of 
the dental apparatus, animal life would not increase very much beyond the single-cell forms. The animal life in such case would necessarily have remained in the elementary stage, or would have been represented by such animals as we find today that are devoid of teeth, and which are of very simple structure, being composed of only a few cells. and some of them compused of only a single cell.

If we begin with the study of those organisms which are composed of very simple cell masses, whose alimentary tract consists of a simple sack with a single opening, we will find even at this stage that the cells surrounding the oral opening become larger, and are the beginning of the development of the

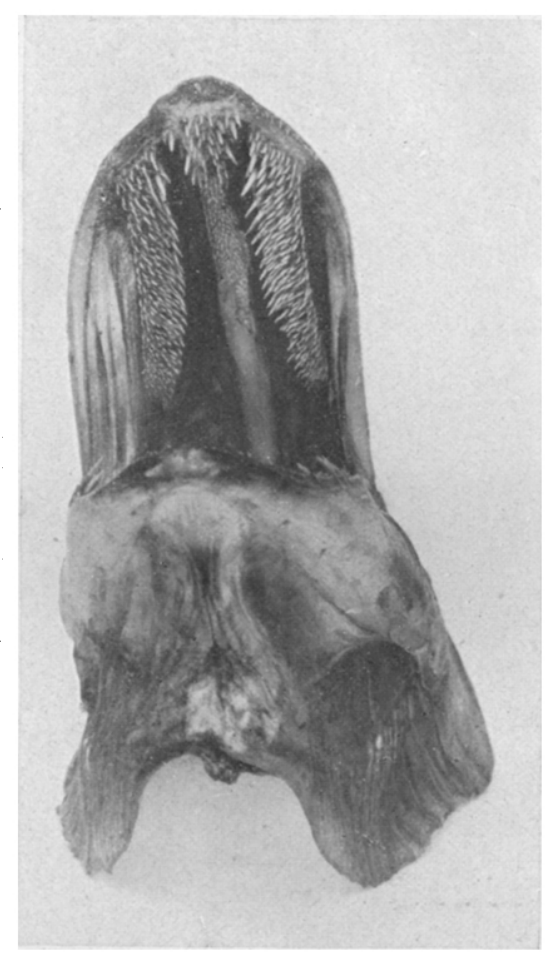

Hig. 2-Teeth of Therel (fisor luchs showing teeth win yomer and palates.

dental apparatus. As we approach the insect life we do not find, as a rule, true teeth, but nature has made a provision for a dental apparatus by supplying the animal with serrated jaws, which are analogous to teeth, with which he is able to secure his food, and with which he is able to perform the secondary function of the teeth-namely, that of defense and offense. The invertebrate, as a rule, are devoid of true teeth, but when we pass to the vertebrate we find teeth are the common rule. In fact, in the lower vertebrate we find that the dental apparatus reaches a high degree of perfection before any of the other organs attain a similar degree of completion. In the lower forms of fish, which are represented by the cartilaginous species, of which the shark is an example, we find a dental apparatus (Fig. 1) which is particularly suited to the animal's needs, and which apparatus has largely been responsible for the continued ex- 
istence of that primitive animal even up to the present time, when it is forced to live in an environment which tends to destroy it in great numbers. The dental apparatus of the shark is particularly efficient for its needs because it is composed of a large number of teeth. These teeth are attached by fibrous membrane, but are of continuous succession, and it is this continuous succession and rapid development that has enabled the dental apparatus to serve the animal so efficiently. The teeth of a shark are simply modified placoid scales, which have been carried into the oral cavity by a process of development and have become larger to serve the needs of the animal. We may consider the dental apparatus of the shark as representing one of the first set of teeth used for the economy of the fish and which were necessary for its existence.

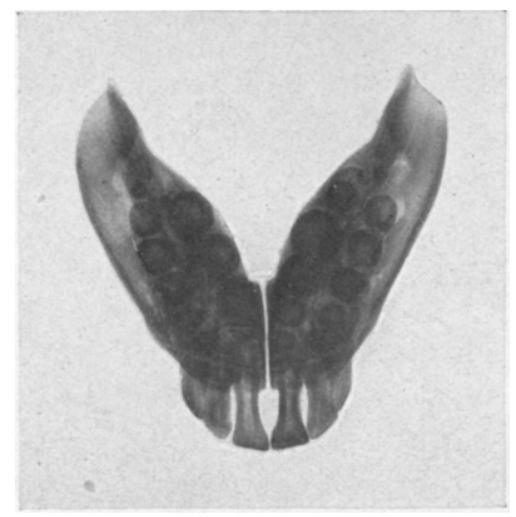

Fig. 3.-Sargus, incisor-form teeth ankylosed to jaw. Posterior teeth for crushing. Anterior teeth for incision. Heterodont. (Author's collection-Roentgenogram by Dr. E. H. Skinner.)

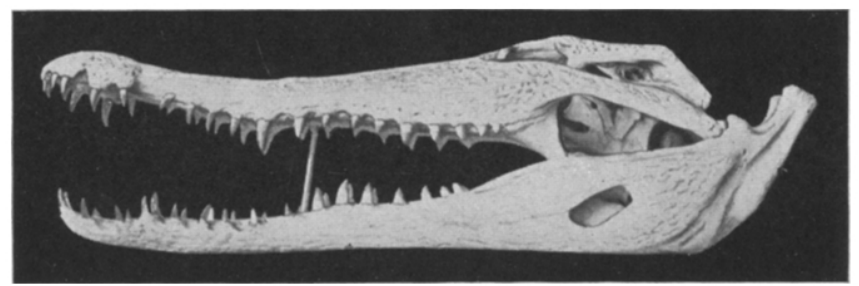

Fig. 4.-Teeth of Crocodilus niloticus.

In various bony fish we find the dental apparatus has reached a higher state of perfection in that certain teeth have become specialized and have been made to perform a certain definite function. As a result, the economic condition of the animal has been greatly increased, and it has been able to utilize a class of food which cannot be consumed by the shark. In the pickerel (Fig. 2) we find teeth placed upon the palate and vomer to perform the function of prehension and deglutition, while the teeth on the mandible perform the function of prehension. Those who indulge in the sport of catching pickerel may never have understood that the peculiar habits of the animal were due to the teeth it possessed. If toothless pickerel were developed, the tactics of angling for the fish would have to be changed as the habits of the toothless pickerel would be entirely altered, and it would be forced to eat a different kind of food. 
In fact, the very nature of every animal depends on the teeth. Fig. 3 shows a dental apparatus of the sargus, whose teeth are decidedly different from those of the pickerel, and which necessarily leads a very different life and eats other kinds of food.

In an economic consideration of the teeth as a factor in the production of and influence on animal life, we leave the fish and pass to the reptites, of which there arc many kinds. Invcstigations inform us that ages ago the world was largely inhabited by enormous reptiles, whose dental apparatus was very similar to that of the alligator and crocodile of today. The dental apparatus of the alligator and crocodile is not very efficient, but the animal has managed to exist

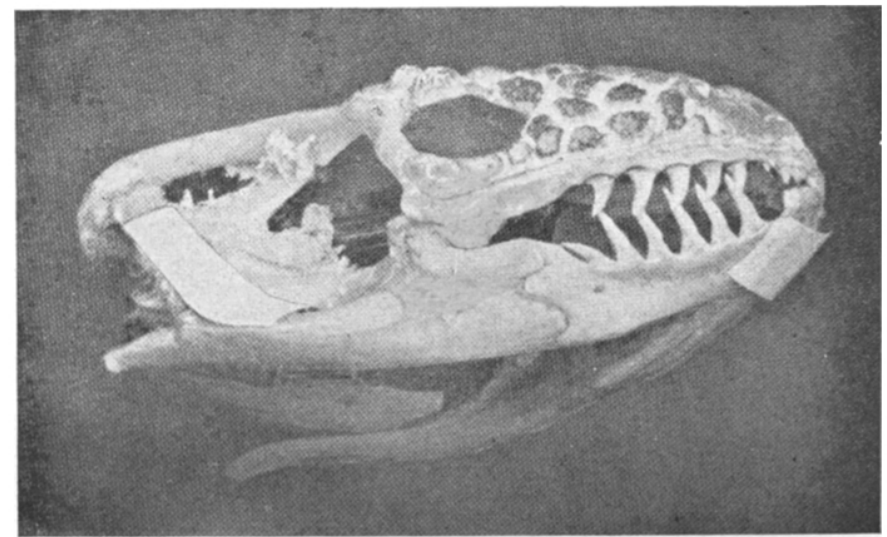

Fig. 5 - Teeth of Gila Monster (Heloderma).

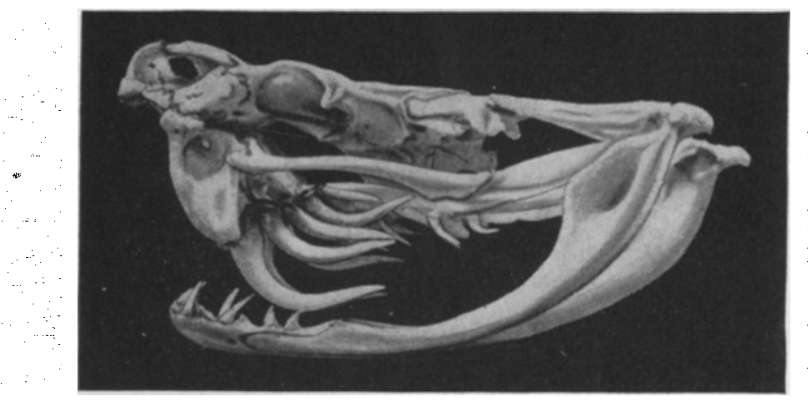

Fig. 6.-Teth of Rattlesnake (Crotalus aramanteus). Highy specialized poison fangs.

because it has lived in certain haunts that are diffictlt for man to explore. The development of their strong exoskeleton has made them immune to the attack of most animals except man, and therefore they still exist in large numbers. The dental apparatus of the alligator and crocodile, while not so efficient as that of some of the other reptiles, is, however, suited to their particular needs, and is of sufficient utility for the class of food found in the labitats of those animals. Other animals closely related to the alligator and crocodile, such as the various kinds of lizards, have also adapted themselves to certain environments and their dental apparatus has likewise become of economic importance. We refer to the gila monster (Fig. 5) which inhabits the desert, and has a dental apparatus suited to its particular needs in its environments. Of the other rep- 
tiles, we may refer to the snakes, which are poisonous and nonpoisonous, both kinds having dental apparatus that is very efficient. Of course, the poisonous snake possesses a dental apparatus that is specialized to a greater extent than that of the nonpoisonous, and the abhorence in which the entire snake family is held is based on the characteristics borne by the poisonous snake. The dental apparatus of the poisonous snake is efficient to a high degree (Fig. 6) and seems to be developed to a condition of effective preparedness, with the result that all of its nonpoisonous cousins are placed in the same category and are made to unjustly suffer for its sins. In America we have only two families

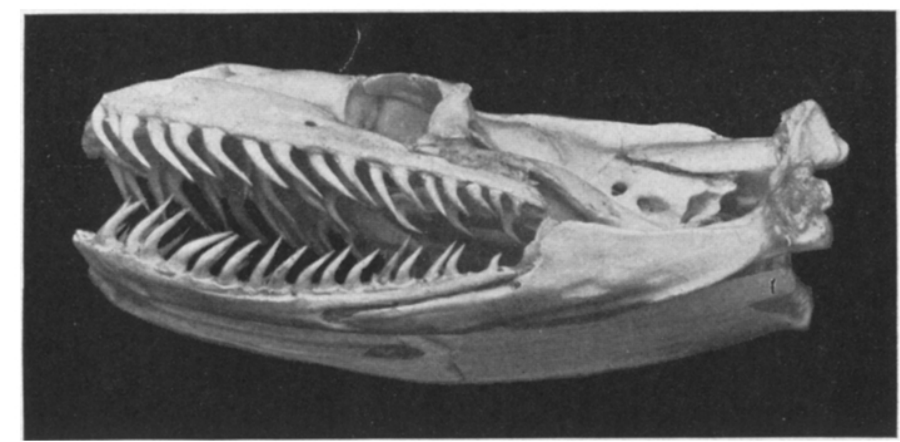

Fig. 7.-Teeth of Python regiss, used for prehension and deglutition.

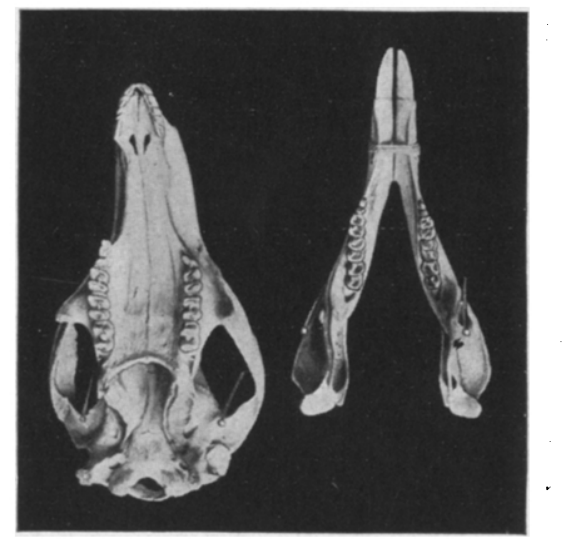

Fig. 8.-Teeth of Kangaroo (Macropus giganteus).

of poisonous snakes that exist to any considerable extent today-namely, the rattlesnake and the copperhead. We have many varieties of nonpoisonous snakes that possess dental apparatuses which are efficient for securing food and which are necessary for the life of the animal. Nonpoisonous snakes may possess a large number of teeth, which are used for the functions of deglutition and prehension (Fig. 7). The poisonous snake as shown in Fig. 6, has fewer teeth, but their efficiency is increased by continuous succession, as the animal is never without a set. Nature has provided the lower animals with a dental apparatus which suits their needs, and, while it may be defective in some respects in certain animals, it has enabled the animals to exist during their allotted terms of lives. 
We find some animals are devoid of teeth, but they possess analogous apparatuses that are highly developed. We refer to the beaks of various birds, and these beaks may be considered to be more highty specialized, from a dental standpoint, than some of the dental apparatuses of lower animals, as geological remains show that the earlier types of birds possessed teeth.

Of the higher animals we may mention the marsupials, a class of animals that have ceased developing at a stage which most other animals passed years ago. From a dental standpoint, however, the marsupials are very well supplied, and, in fact, are better supplied than some of the mammals. The kangaroos of Australia (Fig. 8) possess a dental apparatus which is a highly specialized herbivorous type, and enables them to lead a life and secure food where it would be difficult for other herbivorous animals, or even rodents, to exist. The arrangement of the upper and lower incisors makes it possible for the animal to obtain food where such animals as the sheep and cow would starve. and presents a case where the very existence of the animal depends on the den-

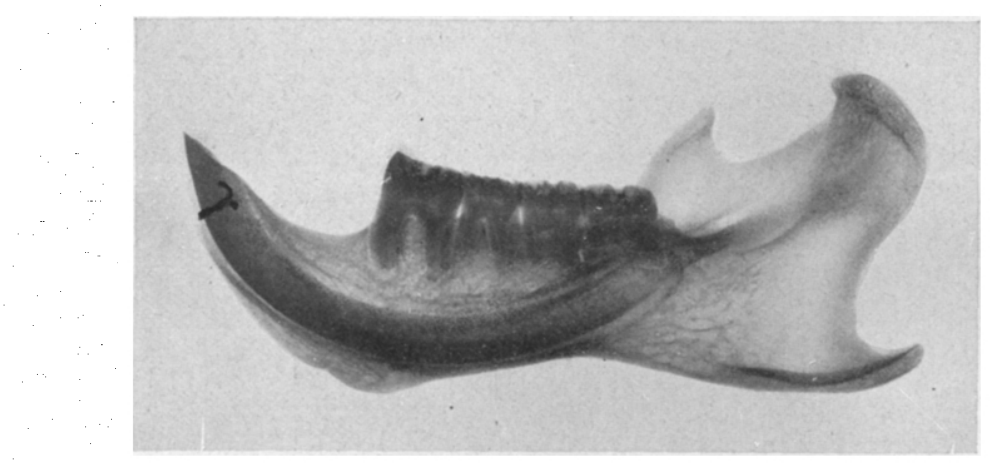

Fig. 9. Rentgenogran of jaw of Wondeluck (Avtomw monts) (By Dr fo ll skinmer

tal apparatus. The dental organs of the American opossum (Fig. 9) are also very efficient, but in this case the teeth; as well as other portions of the animals, are passing through an evolutionary stage, and represent a condition between the carnivorous and herbivorous dentition." In fact, some of the teeth of the opossum resemble those of the carnivorous animal, while other teeth resemble those of the herbivorous, The specialization of the dental apparatus of an animal docs not necessarily depend on whether it is a marsupial or whether the young are born in the nature stage, for, as has been stated, the teeth of the kangaroo are more highly specialized than those of some of the higher mammals. There is a little marsupial in Madagascar that resembles a squirrel and has a rodent dentition-that is, the animal possesses large scalpriform incisors, whel grow from persistent germs, and it the peculiar teeth of the animal which enable il to secure a diet which the other marsupials cannot obtain. Rodents represent a class of animals which, from : dental standpoint, is very interesting, for the very existence of practically all rodents depends on their dental apparatus. We cannot imagine that any rodent would exist very long if it were to lose the incisors, as they are the more important teeth. Of course, the loss of the molars wottd be inconvenient, and 
their absence would probably hasten the death of the animal. More or less is known about the wonderful habits of the beaver (Fig. 10) and the great intellect which the animal displays, but this intellect would be absolutely useless and the animal would be extinct as a class if it were not for its peculiar teeth. The teeth are useful not only as organs for securing food, but also as tools with which to do the particular type of building for which they are noted. In many of our American cities some of the parks are the abiding places of a largc

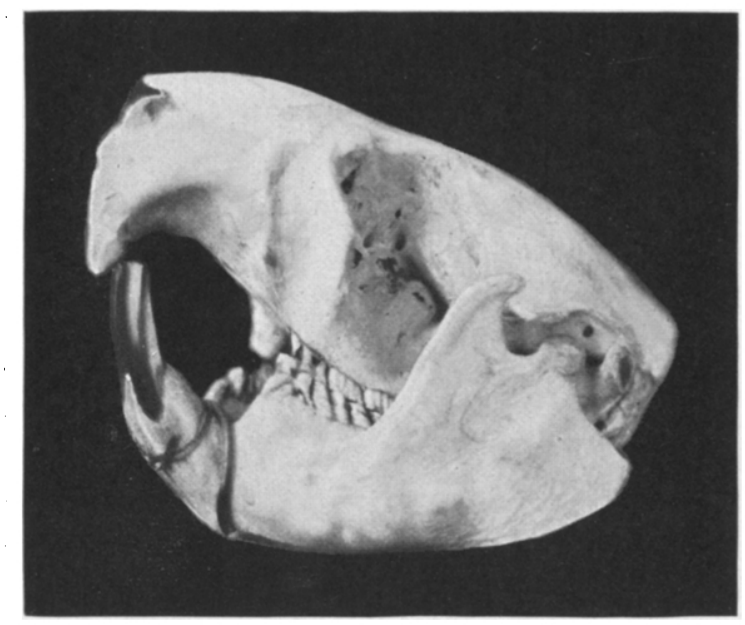

Fig. 10.-Teeth of Beaver (Castor canadensis). Side view.

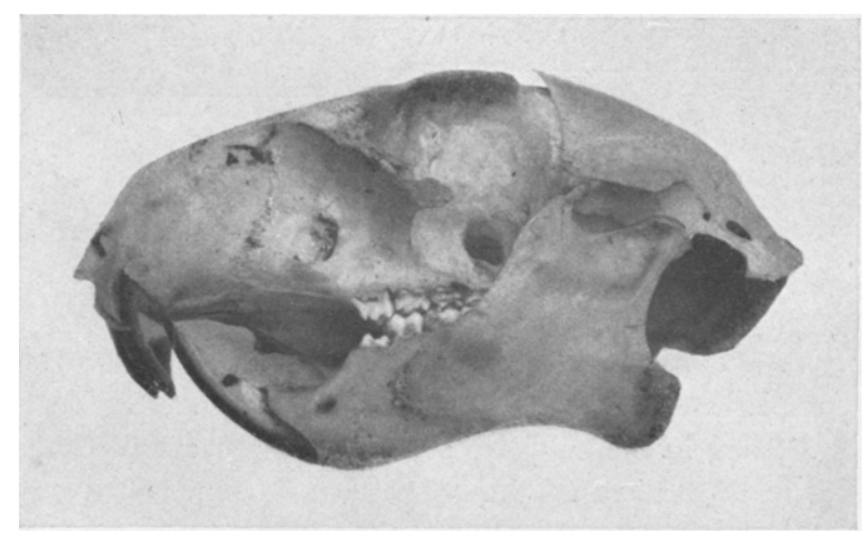

Fig. 11.-Teeth of Squirrel (Scurius niger).

number of squirrels, which seems to be the only animal that is able to exist with any degree of safety in those surroundings, and this is because the squirrel (Fig. 11) is able to obtain food in a way that is denied the majority of other animals. The squirrel is able to open nuts, that are found on some trees in the parks it frequents, and the formation of its dental organs has enabled it to take up abodes where no other animals could exist.

The statement has been made that, should certain animals lose their teeth - or by some means lose the use of their teeth-they would soon die, and an example of such an occurrence is illustrated in Fig. 12. Here is shown the 
skull of a squirrel which met with an accident, and the central incisors, failing to occlude, continued to grow from a persistent pulp until the animal starved to death as a result of the accident.

Of the carnivorous animals the lion (Fig. 13) is a good example. The position which the lion occuptes in the animal kingdom, both actually and theoretically, being called the king of beasts, is because of the dental apparatus which it possesses. The carnivorous animals do not possess certain teeth because they are carnivorous, but, conversely, they are carnivorous because they possess that type of teeth. Just what has been responsible for the development of the dental apparatus of the carnivorous animals will probably never be known, but from some cause such a set of teeth has developed, and consequently the entire nature of the animal must conform to the teeth. We are not prepared to state positively that a certain dental apparatus has developed to meet the particular nceds of the animal, but we will say that, after it has once developed.

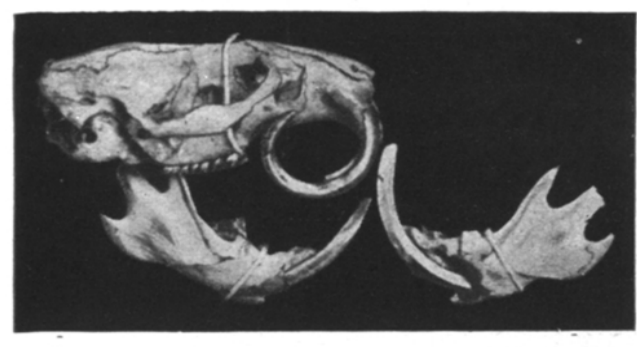

A

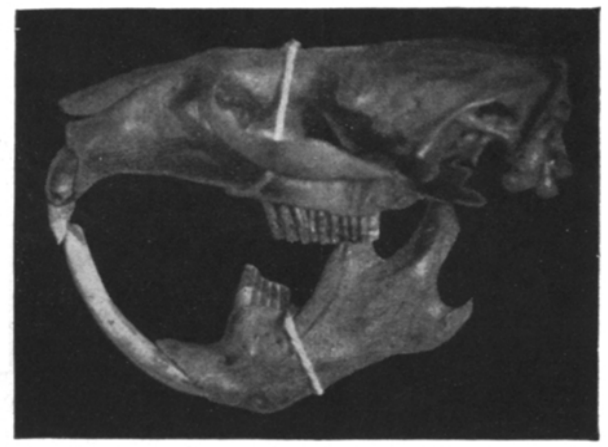

B

Iig. 12.- Skults of Squirels, showing exeessive growth of incisors as a result of injury

the animal is dependent on it for its continued existence. In other words, if a carnivorous animal were to lose the canine teeth, it would die in a short time. The teeth of the herbivorous animals (Fig. 14) are just as important for their purpose as the teeth of the carnivorous animals, and have been specialized in a manner that compels the animal to follow a certain habit. We are reminded of the story of the dog in the manger, which could not eat the hay, and, because he could not eat it, refused to let the ox have it, which may have made the impression as being a fable, but which nevertheless has a certain scientific bearing when viewed from a scientific standpoint.

These few examples in regard to the teeth of certain animals will, we believe, enabte the reader to understand what we mean by the statement that the teeth are economical factors in the preservation of animal life. If, therefore, the teeth have been so important a factor to the lower animals, the question naturally arises how much of a factor are they in the economy of the human family today? We are of the opinion that they play a much greater part in the individual than has been attributed to them, and we believe that an examination of the records of men who have attained great success today would disclose the fact that they obtained their greatest achievements during the time 
when their dental apparatus was in the best condition. We can make the statement with little fear of contradiction that an individual after he has los: his teeth is making a losing fight. We believe that if in the case of two boys each twelve years of age and of the same physical development and same intelligence, one should have all his teeth extracted, and even supplied with the best artificial denture, the one with the artificial teeth would be a very poor second to the individual with natural teeth. In fact, we feel that it is impos.

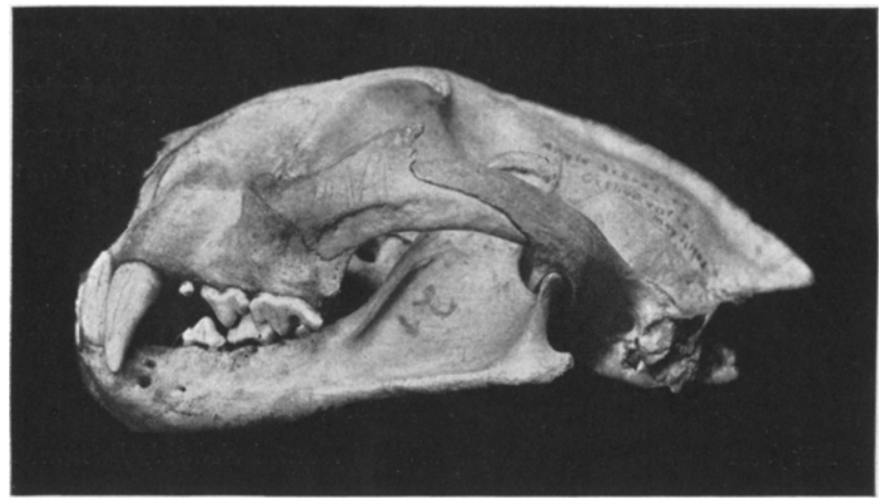

Fig. 13,-Teeth of Mountain Lion. Side view.

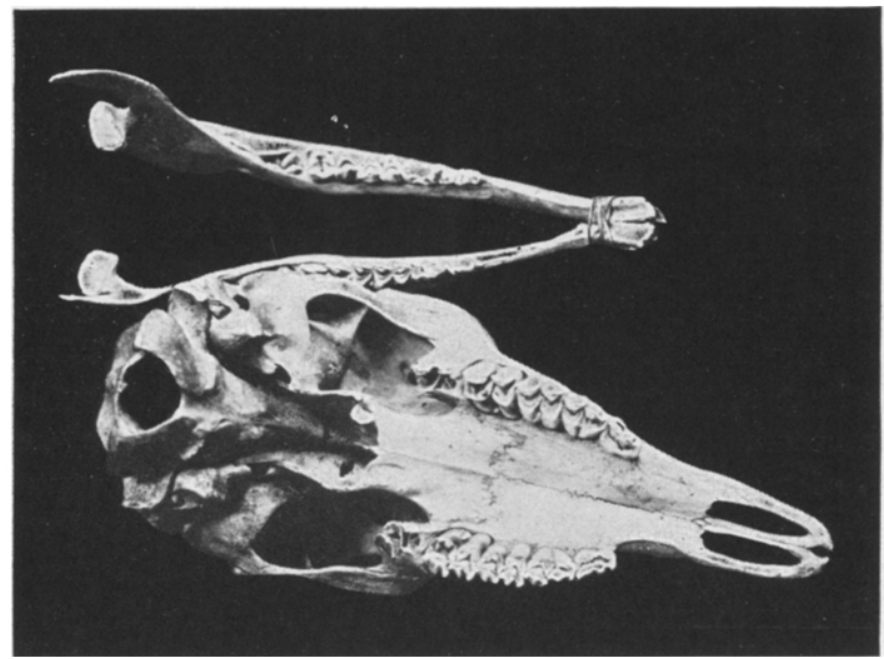

Fig. 14.-Occlusal view of teeth of Antelope (species unknown).

sible for an individual to reach his highest degree of efficiency unless all of hi: teeth are in normal occlusion and performing their proper function. Even the loss of one tooth will impair the masticating efficiency of the dental apparatus and this impairment of the dental apparatus will correspondingly lessen the efficiency of the individual. In our observation of people, if we find a man 70 years old who possesses all of his natural teeth, he will be an individual who is vigorous and who possesses physical and mental strength far superior to another man of 70 years who lost all his teeth at the age of 40 . 
If, as explained above, the teeth have played such an important part in the development of lower animals, it is logical to conclude that they have been an important factor in the development of man, and, if they have been such essential organs to men's progress, it is illogical to suppose that in the course of time they will lose their efficiency and cease to be of economic importance in the life of the human being. While it is a fact that individuals can live without teeth (they can be supplicd with certain artificial substances) it is our opinion that the individual who possesses artificial teeth will be at a disadvantage when compared with the individual with a normal set of teeth. It therefore becomes our duty to impress our patients with the fact that malocclusions should be treated, not on account of the esthetic feature, but because of the importance of well-arranged teeth as organs of mastication, and the influence which they will have on the physical and mental development of the individual.

\title{
ORTHODONTIA-ITS PLACE IN DENTAL EDUCATION*
}

\author{
BY IAWRENCE W. BAKER, D.MD. \\ Assistant Professor of Orthodonita, Harzard Dental School, Boston Mass.
}

I' $I$ ' is a generally observed fact that the most progressive and active minds in our profession are interested in the training of those who are to enter our ranks, in other words, they are interested in the advancement of dental cducation. Therefore I thought that my fellow graduates of the Angle School might be interested to hear something about the methods and see some results of these methods in teaching orthodontia in the Dental School of Harvard University.

At the very outset $I$ would like to state the aims of the Orthodontia Department. While it is not our purpose to educate, at least in the regular curriculum, specialists in orthodontia, we do regard the study of orthodontia as one of the fundamentals in teaching the modern student of dentistry. The study of orthodontia links together the student's knowledge of anatomy, histology and embryology as no other dental study can, for these subjects are the very structural elements of the theory of orthodontia. The student's mental horizon is furthermore broadened by a knowledge of comparative dental anatomy, that fascinating study which leads the diligent student on to a keener appreciation of the wonderful variations and architectural plans of the human types, gained through the study of the dental systems of the lower animals with their mar velous physiological adaptations to the foods and habits of the species, all of which reflect the great principles of evolution.

Practical orthodontia is also very important in revealing to the student the wonders of the dental apparatus, for here this most intricate piece of nature's work is studied in its entirety, whereas in the various studies pertaining to operative and mechanical dentistry the students' attention is so focused on some manipulative process that they are apt to consider the dental system as made up of separate units, the relation of these units, one to another is lost sight of 